Commentary

www.mdpi.com/journal/jintelligence

\title{
Zeroing in on the Genetics of Intelligence
}

\author{
Ruben C. Arslan ${ }^{\dagger} *$ and Lars Penke ${ }^{\dagger}$ \\ Biological Personality Psychology and Psychological Assessment, Institute of Psychology, Georg \\ August University Göttingen, Goßlerstr. 14, 37073 Göttingen, Germany; \\ E-Mail: lpenke@uni-goettingen.de \\ $\dagger$ These authors contributed equally to this work. \\ * Author to whom correspondence should be addressed; E-Mail: ruben.arslan@gmail.com; \\ Tel.: +49 551/39-20704.
}

External Editor: Paul De Boeck

Received: 28 November 2014 / Accepted: 16 April 2015 / Published: 20 April 2015

\begin{abstract}
Despite the high heritability of intelligence in the normal range, molecular genetic studies have so far yielded many null findings. However, large samples and self-imposed stringent standards have prevented false positives and gradually narrowed down where effects can still be expected. Rare variants and mutations of large effect do not appear to play a main role beyond intellectual disability. Common variants can account for about half the heritability of intelligence and show promise that collaborative efforts will identify more causal genetic variants. Gene-gene interactions may explain some of the remainder, but are only starting to be tapped. Evolutionarily, stabilizing selection and selective (near)-neutrality are consistent with the facts known so far.
\end{abstract}

Keywords: intelligence; molecular genetics; behavior genetics; evolution

Observers of the literature on the genetics of intelligence may be forgiven for thinking that progress is slow. In fact, after decades of research, molecular geneticists have delivered few replicable genetic variants associated with intelligence.

Although we know that intelligence is substantially heritable ( $40 \%-80 \%$ in adulthood in developed societies), Chabris and colleagues [1] rightly concluded that few, if any, reported associations with genetic markers are replicable. Initial reports from candidate gene studies were not replicated in 
increasingly well-powered genome-wide association studies (GWAS). The most powerful GWAS meta-analysis so far only reported 13 results with miniscule effects and a polygenic prediction explaining $1.3 \%$ of the IQ variance [2].

A promising explanation for this shortfall seemed to be that newly occurring mutations and rare genetic variants, both not tagged well in GWAS, introduce variation to intelligence. Sure enough, research on intellectual disability (ID) identified new mutations as a main cause. Experience with other complex human traits seemed to hold promise that variants in genes known through Mendelian (monogenic) disorders would also predict normal variation. Yet, genetic variation in known ID genes did not live up to this promise at present sample sizes [3,4]. Studies on parental age, a well-validated proxy variable for new mutations not shared with the parents [5], showed associations with ID and autism. However, any such association for intelligence in the normal range disappeared after controlling for parental confounds [6], even in sibling comparisons of half a million men [7]. Contemporary genome sequencing studies corroborated paternal age associations for ID and autism by comparing the genomes of affected children and their parents and linking cases to new mutations [8]. However, a small initial study purporting to link IQ to rare genetic copy number variant (CNV) load was not replicated $[9,10]$. A recent exome (the parts of the genome that code for proteins) genotyping study did not find links of accumulated loads of rare variants to intelligence [11].

Still these negative results are far from uninformative. Thanks to the stringent statistical standards adopted in genetics nowadays, many false positives were rooted out or prevented. Collaborative efforts, yielding very large sample sizes, provide a ceiling on possible effect sizes, and confidence that reported null findings are true negatives. We are slowly learning where the genetic basis of intelligence is not, and thus also where it can still be.

One promising approach seems to be based on correlating estimates of the very low genetic similarity between individuals in broad population samples (GCTA) with their similarity in intelligence. Using GCTA several groups $[1,12,13]$ showed that a bit more than half of the IQ heritability found in twin studies can be explained based on common genetic variants alone. This implies that some of the heritable variability is explained by very large numbers of genetic variants, each individually accounting for very little variance. Sample sizes on the order of hundreds of thousand may be needed to actually explain substantial variance by causal common genetic markers in exploratory analyses [12], although new approaches are starting to supersede both ill-fated candidate gene analyses and purely exploratory GWAS, through e.g., pre-selecting certain genetic variants via their association with education [14] or hypothesis-driven gene set enrichment [15].

What about the rest though? Extended twin-family studies have given us estimates of non-additive genetic variation $(27 \%, 19 \%)$ for intelligence that are about $60 \%$ of additive variation $(44 \%, 32 \%)[16,17]$. Dominance and epistasis (interactions between genetic variants at the same and different loci) may thus well make up a sizable amount of the heritability of intelligence. Pinpointing such interactions between genes at a molecular level is daunting due to the explosion of parameters. As a first step, molecular geneticists can examine homozygosity [18]. Not much can be said so far about gene-environment interactions, but they remain a plausible explanatory factor.

What does all this imply for the evolutionary forces maintaining genetic differences in intelligence $[19,20]$ ? New mutations of strong effect play a lead role in the genesis of intellectual disability, but these tend to not stay in the population for long. In contrast, recent results suggest that in 
the normal range of intelligence new mutations play a minor role. However, gaps in the data remain and researchers have yet to tap into burdens of accumulated rare genetic variants in the introns (affecting gene regulation) or into non-SNP mutations (e.g., structural variation) [3]. Selective (near)-neutrality seems consistent with the existing evidence for the large fraction of heritability explained by common variants [13], since the jury is still out for the question if phenotypic links between intelligence and fitness components (fertility, longevity, sexual attractiveness, mating success) really make, or historically made, intelligence differences in the normal range visible to evolutionary selection at all. Alternatively, if genetic interactions play the role that we ascribe to them here, we also need to consider stabilizing selection, where selective pressures have worked to make intelligence robust to genetic and environmental perturbations in either direction [21], not to increase it as much as possible. Because of that possibility, researchers should not build the assumption that very high IQ is continuous with normal intelligence into their studies by default $[3,4,21]$. Once enough data is in, complex models and simulations will allot roles to these mechanisms. For now, we know that the result will not be simple.

\section{Author Contributions}

Both authors contributed to the conception and writing of this commentary equally.

\section{Conflicts of Interest}

The authors declare no conflict of interest.

\section{References}

1. Chabris, C.F.; Hebert, B.M.; Benjamin, D.J.; Beauchamp, J.; Cesarini, D.; van der Loos, M.; Johannesson, M.; Magnusson, P.K.; Lichtenstein, P.; Atwood, C.S.; et al. Most reported genetic associations with general intelligence are probably false positives. Psychol. Sci. 2012, 23, 1314-1323.

2. Davies, G.; Armstrong, N.; Bis, J.C.; Bressler, J.; Chouraki, V.; Giddaluru, S.; Hofer, E.; Ibrahim-Verbaas, C.A.; Kirin, M.; Lahti, J.; et al. Genetic contributions to variation in general cognitive function: A meta-analysis of genome-wide association studies in the CHARGE consortium ( $N=53949)$. Mol. Psychiatry 2015, 20, 183-192.

3. Franić, S.; Groen-Blokhuis, M.M.; Dolan, C.V.; Kattenberg, M.V.; Pool, R.; Xiao, X.; Scheet, P.A.; Ehli, E.A.; Davies, G.E.; van der Sluis, S.; et al. Intelligence: shared genetic basis between Mendelian disorders and a polygenic trait. Eur. J. Hum. Genet. 2015, doi:10.1038/ejhg.2015.3.

4. Franić, S.; Dolan, C.V.; Broxholme, J.; Hu, H.; Zemojtel, T.; Davies, G.E.; Nelson, K.A.; Ehli, E.A.; Pool, R.; Hottenga, J.-J.; et al. Mendelian and polygenic inheritance of intelligence: A common set of causal genes? Using next-generation sequencing to examine the effects of 168 intellectual disability genes on normal-range intelligence. Intelligence 2015, 49, 10-22.

5. Ségurel, L.; Wyman, M.J.; Przeworski, M. Determinants of mutation rate variation in the human germline. Annu. Rev. Genomics Hum. Genet. 2014, 15, 47-70. 
6. Arslan, R.C.; Penke, L.; Johnson, W.; Iacono, W.G.; McGue, M. The effect of paternal age on offspring intelligence and personality when controlling for parental trait levels. PLOS ONE 2014, 9, e90097.

7. D’Onofrio, B.M.; Rickert, M.E.; Frans, E.; Kuja-Halkola, R.; Almqvist, C.; Sjölander, A.; Larsson, H.; Lichtenstein, P. Paternal age at childbearing and offspring psychiatric and academic morbidity. JAMA Psychiatry 2014, 71, 432-438.

8. Gilissen, C.; Hehir-Kwa, J.Y.; Thung, D.T.; van de Vorst, M; van Bon, B.W.M.; Willemsen, M.H.; Kwint, M.; Janssen, I.M.; Hoischen, A.; Schenck, A.; et al. Genome sequencing identifies major causes of severe intellectual disability. Nature 2014, 511, 344-347.

9. MacLeod, A.K.; Davies, G.; Payton, A.; Tenesa, A.; Harris, S.E.; Liewald, D.; Ke, X.; Luciano, M.; Lopez, L.M.; Gow, A.J.; et al. Genetic copy number variation and general cognitive ability. PLOS ONE 2012, 7, e37385.

10. McRae, A.F.; Wright, M.J.; Hansell, N.K.; Montgomery, G.W.; Martin, N.G. No association between general cognitive ability and rare copy number variation. Behav. Genet. 2013, 43, 202-207.

11. Marioni, R.E.; Penke, L.; Davies, G.; Huffman, J.E.; Hayward, C.; Deary, I.J. The total burden of rare, non-synonymous exome genetic variants is not associated with childhood or late-life cognitive ability. Proc. R. Soc. B Biol. Sci. 2014, 281, 20140117.

12. Kirkpatrick, R.M.; McGue, M.; Iacono, W.G.; Miller, M.B.; Basu, S. Results of a "GWAS Plus:" General cognitive ability is substantially heritable and massively polygenic. PLOS ONE 2014, 9, e112390.

13. Plomin, R.; Deary, I.J. Genetics and intelligence differences: Five special findings. Mol. Psychiatry 2014, 20, 98-108.

14. Rietveld, C.A.; Esko, T.; Davies, G.; Pers, T.H.; Turley, P.; Benyamin, B.; Chabris, C.F.; Wmilsson, V.; Johnson, A.D.; Lee, J.J.; et al. Common genetic variants associated with cognitive performance identified using the proxy-phenotype method. Proc. Natl. Acad. Sci. 2014, 111, 13790-13794.

15. Hill, W.D.; Davies, G.; van de Lagemaat, L.N.; Christoforou, A.; Marioni, R.E.; Fernandes, C.P.D.; Liewald, D.C.; Croning, M.D.R.; Payton, A.; Craig, L.C.A.; et al. Human cognitive ability is influenced by genetic variation in components of postsynaptic signalling complexes assembled by NMDA receptors and MAGUK proteins. Transl. Psychiatry 2014, 4, e341.

16. Vinkhuyzen, A.A.E.; Sluis, S.; van der Maes, H.H.M.; Posthuma, D. Reconsidering the heritability of intelligence in adulthood: Taking assortative mating and cultural transmission into account. Behav. Genet. 2012, 42, 187-198.

17. Chipuer, H.M.; Rovine, M.J.; Plomin, R. LISREL modeling: Genetic and environmental influences on IQ revisited. Intelligence 1990, 14, 11-29.

18. Power, R.A.; Nagoshi, C.; DeFries, J.C.; Donnelly, P.; Barroso, I.; Blackwell, J.M.; Bramon, E.; Brown, M.A.; Casas, J.P.; Corvin, A.; et al. Genome-wide estimates of inbreeding in unrelated individuals and their association with cognitive ability. Eur. J. Hum. Genet. 2013, 22, 386-390.

19. Arslan, R.C.; Penke, L. Evolutionary genetics. In Handbook of Evolutionary Psychology; Buss, D.M., Ed.; Wiley: New York, NY, USA, in press. 
20. Penke, L.; Denissen, J.J.A.; Miller, G.F. The evolutionary genetics of personality. Eur. J. Personal. 2007, 21, 549-587.

21. Luciano, M.; Svinti, V.; Campbell, A.; Marioni, R.E.; Hayward, C.; Wright, A.F.; Taylor, M.S.; Porteous, D.J.; Thomson, P.; Prendergast, J.G.; et al. Exome sequencing to detect rare variants associated with general cognitive ability: A pilot study. Twin Res. Hum. Genet. 2015, doi:10.1017/thg.2015.10.

(C) 2015 by the authors; licensee MDPI, Basel, Switzerland. This article is an open access article distributed under the terms and conditions of the Creative Commons Attribution license (http://creativecommons.org/licenses/by/4.0/). 